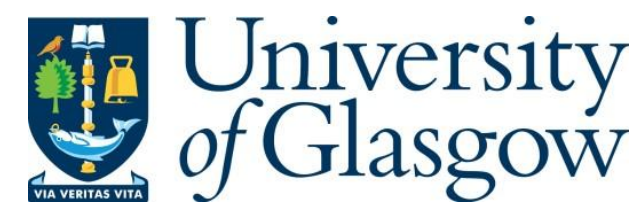

Zare-Behtash, H., Gongora-Orozco, N., and Kontis, K. (2011) Effect of primary jet geometry on ejector performance: a cold-flow investigation. International Journal of Heat and Fluid Flow, 32 (3). pp. 596607. ISSN 0142-727X(doi:10.1016/j.ijheatfluidflow.2011.02.013)

Copyright @ 92011 Elsevier

A copy can be downloaded for personal non-commercial research or study, without prior permission or charge

Content must not be changed in any way or reproduced in any format or medium without the formal permission of the copyright holder(s)

When referring to this work, full bibliographic details must be given

http://eprints.gla.ac.uk/84641/

Deposited on: 07 January 2014

Enlighten - Research publications by members of the University of Glasgow http://eprints.gla.ac.uk 


\title{
Effect of Primary Jet Geometry on Ejector Performance:
}

\section{A Cold-Flow Investigation}

\author{
H. Zare-Behtash, ${ }^{*}$ N. Gongora-Orozco, and K. Kontis \\ School of MACE, The University of Manchester, M60 1QD, UK
}

\begin{abstract}
The following cold-flow study examines the interaction of the diffracted shock wave pattern and the resulting vortex loop emitted from a shock tube of various geometries, with an ejector having a round bell-shaped inlet. The focus of the study is to examine the performance of the ejector when using different jet geometries (primary flow) to entrain secondary flow through the ejector. These include two circular nozzles with internal diameters of $15 \mathrm{~mm}$ and $30 \mathrm{~mm}$, two elliptical nozzles with minor to major axis ratios of $a / b=0.4$ and 0.6 with $b=30 \mathrm{~mm}$, a square nozzle with side lengths of $30 \mathrm{~mm}$, and two exotic nozzles resembling a pair of lips with axis ratios of $a / b=0.2$ and 0.5 with $b=30 \mathrm{~mm}$. Shock tube driver pressures of $P_{4}=4,8$, and $12 \mathrm{bar}$ were studied, with the pressure of the shock tube driven section $P_{1}$ being atmospheric. High-speed schlieren photography using the Shimadzu Hypervision camera along with detailed pressure measurements along the ejector and the impulse created by the ejector were conducted.
\end{abstract}

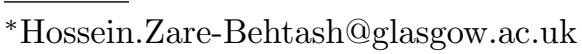




\section{INTRODUCTION}

Non-circular jets provide efficient passive flow control at relatively low cost since they rely solely on changes in the geometry of the nozzle. ${ }^{1}$ Non-circular injectors such as elliptic, triangular, and square nozzles are used to improve combustion processes by augmenting heat release, reducing emissions, and improving flame stability. ${ }^{2}$ The technological challenge of mixing enhancement in compressible flows stems from the inherently low growth rates of supersonic shear layers. ${ }^{3}$ Investigation into the properties of non-circular jets has been motivated by their enhanced characteristic entrainment properties relative to those of comparable circular jets. ${ }^{4,5}$

However, the benefits of non-circular jets are entwined with the complicated motion of the flow. Figure 1 depicts the motion of elliptic and square vortex loops as they propagate downstream and go through the phenomenon of axis-switching. ${ }^{6}$ Also, with increasing flow Mach number compressibility effects play a large role in the behaviour of the flow. Figure 2 shows how the formation of an embedded shock wave within the primary vortex loop leads to the deceleration of the flow ahead of the primary vortex loop and the creation of an secondary counter rotating vortex loop. ${ }^{7}$

One way of incorporating the benefits of air breathing into rocket-based launch vehicles is through the use of an ejector system. Ejectors are fluid pumps that are used to entrain secondary flows using a primary flow. For propulsion applications, this entrainment can augment thrust compared to that generated by the primary flow alone and thereby increase performance. This idea is central to the development of rocket-based combined cycle $(\mathrm{RBCC})$ engines and pulse detonation engines $(\mathrm{PDEs})^{8,9}$ in which it is the ejector effect that is primarily responsible for any increased performance over traditional rocket systems during the initial phases of launch. ${ }^{10}$ PDEs are unsteady propulsion devices that produce periodic impulse by utilising repetitive detonations. Upon diffraction of the detonation wave from a PDE, a vortex loop is formed immediately behind it. The interaction of the blast wave and consequent vortex loop generated at the nozzle exit can affect the performance of the ejector. This is due to the different entrainment rates of vortex loops of various shapes.

Non-detonational computational studies have highlighted the importance of the starting vortices, precursor shocks, and direct pressure loads created by the gas-dynamic (shocktube) processes within the ejector to the overall thrust-augmentation performance of the 
system. High thrust augmentation for PDE-ejector applications is achievable once the gasdynamics and the flow interactions of the PDE-ejector system are understood. This involves understanding of the jet structure and also the vortex loops structures encountered in such flows. These data will be valuable for calibrating computational fluid dynamics codes and ultimately for the optimisation of PDE and PDE-ejection configurations for propulsion applications.

\section{EXPERIMENTAL SETUP}

\section{A. Shock Tube}

Experiments were carried out using air as both the driver and driven gas with diaphragm pressure ratios $P_{4} / P_{1}=4,8$, and 12 . With $P_{4}$ being the pressure within the driving compartment of the shock tube, and $P_{1}$ the pressure inside the driven section.

An industrial film diaphragm divides the two sections of the shock tube. The thickness of the diaphragm was chosen to be 23,55 and $75 \mu \mathrm{m}$. The diaphragms were chosen for being the minimum thickness which would sustain the desired pressure without spontaneously rupturing. The bursting of the diaphragm was initiated manually with a plunger. The various shock tube components are outlined in Figure 3The tube was flushed with air after each run to remove any pieces of burst diaphragm.

Various adaptors were designed that could be attached to the end of the circular shock tube section (baseline) with internal diameter $d_{i}=30 \mathrm{~mm}$ and outer diameter $d_{o}=38 \mathrm{~mm}$. This allowed vortex loops of different shapes to be studied. They included two circular nozzles with internal diameters of $15 \mathrm{~mm}$ and $30 \mathrm{~mm}$, two elliptical nozzles with minor to major axis ratios $(a / b)$ of 0.4 and 0.6 with $b=30 \mathrm{~mm}$, a square nozzle with side lengths of $30 \mathrm{~mm}$, and finally two exotic nozzles resembling a pair of lips with axis ratios of $a / b=0.2$ and 0.5 with $b=30 \mathrm{~mm}$ shown in Figure 4 .

Disturbances are formed as a result of the rarefaction waves which reflect from the closed end of the shock tube. A means of eliminating these disturbances is by changing the length of the driver section so that the incident shock and the initial reflected rarefaction wave arrive at the shock tube exit at approximately the same time. The critical length of the driver section for the baseline section of the shock tube was $12.3 d_{i}, 8.53 d_{i}$, and $7.23 d_{i}$ for 
$P_{4} / P_{1}=4,8$, and 12 , respectively. This produces a pulsed upstream condition where the duration and magnitude of the pulse can be controlled up to the nozzles' inlet. ${ }^{11-13}$ The length of the circular driven section (baseline) was $1310.5 \mathrm{~mm}$, with each nozzle $300 \mathrm{~mm}$ in length.

\section{B. Axis-Symmetric Ejector}

The ejector shown in Figure 5, was designed using the optimum dimensions obtained from the study of Glaser et al. ${ }^{14}$ and Wilson et al. ${ }^{16}$ The 'optimum' dimensions pertain to those that would provide the greatest thrust augmentation, which is the design goal of incorporating ejectors. The numbers in the figure correspond to pressure tapping locations. Kulite $X T L-190$ pressure transducers were used to record the pressures along the ejector using Labview. Pressure data were collected at a rate of $200 \mathrm{KHz}$.

The implemented dimensions were: $d_{e j} / d_{i}=3, r_{e j} / d_{e j}=0.2, l_{s t r} / d_{e j}=3, l_{e x h} / d_{e j}=2.36$, where $d_{e j}$ is the diameter of the ejector, $r_{e j}$ is the radius of the ejector inlet, $l_{s t r}$ is the length of the straight section of the ejector, and $l_{e x h}$ is the length of the ejector exhaust section which has a 4 degrees taper. The ejector was placed $2 d_{i}$ from the exit of the shock tube. According to the study of Zare-Behtash et al. ${ }^{17}$ the vortex loop circulation along with vortex loop size increases with distance from the shock tube. This leads to greater entrainment of ambient fluid and hence greater impulse created by the ejector.

To measure the effectiveness of the ejector when using different shock tube exit nozzle geometries, a specially designed plate with four tapping locations along the central axis is utilised. The transducers are attached directly to the plate. The location of the transducers is identified in Figure 6. The impulse measuring system measures the total impulse of the system which includes the driver tube and the ejector.

\section{High-Speed Schlieren Photography}

High-speed schlieren photography ${ }^{18}$ was employed to visualise the flow. The schematic of the setup is given in Figure 7. The setup is identical to that used by Kontis et al., ${ }^{11,19}$ with the only difference being the usage of the Shimadzu high-speed video camera. Schlieren photographs could be captured at rate of $1 M f p s$ with variable exposure time. For the 
current study the recording rate was kept at $32 k f p s$ with an exposure time of $4 \mu s$.

\section{RESULTS AND DISCUSSION}

\section{A. Vortex Loops Interaction with Ejector}

\section{Circular vortex loops}

Figure 8 presents schlieren photographs of the interaction between the circular vortex loops having internal diameters of $15 \mathrm{~mm}$ and $30 \mathrm{~mm}$ with the ejector. The interaction between the reflected shock from the bell shaped inlet of the ejector and the exit of the circular nozzles leads to different flow patterns. For the smaller nozzle, Figure 8(c), the shock merely reflects from the nozzle exit. For the nozzle with internal diameter of $30 \mathrm{~mm}$, however, the diffraction of the shock from the internal wall of the nozzle leads to the generation of a new circular vortex loop shown in Figure $8(\mathrm{~g})$. Soon after the secondary vortex loop enters the ejector, the flow at the inlet separates and a new vortex loop is generated, identified in Figure $8(\mathrm{~h})$.

Pressure measurements corresponding to transducers $T 4$ and $T 18$ (T4 located at the ejector entrance and $T 18$ is the last transducer positioned at the ejector exit) are presented in Figure 9 for the two circular nozzles. The plateau observed in Figure 9(a) after the arrival of the shock front is the time taken for the vortex loop to arrive at the ejector inlet. The arrival of the vortex loop causes an acceleration of the flow and hence, a drop in wall static pressure. Because the vortex loop generated from the nozzle having an internal diameter of $30 \mathrm{~mm}$ is larger, the vortex loop is in closer proximity to the ejector wall and hence it causes a greater acceleration of the flow at the location of transducer 4 .

Although transducer 18 is located $50 \mathrm{~cm}$ downstream of transducer 4 , the reduction in peak pressure, and hence shock strength, is insignificant due to the shock wave travelling inside a confined area. The high pressure within the ejector is maintained because of the multiple reflections which occur inside it. As the spherical diffracted shock wave from the shock tube reflects from the internal walls of the ejector, it initially undergoes regular reflection. As the shock wave travels through the ejector, the point where it touches the reflecting surface encounters a decreasing effective wedge angle and the reflection pattern changes to a Mach reflection. ${ }^{20}$ The triple points joining the Mach stem, the incident shock, 
and the reflected wave, move towards each other from the opposite sides of the ejector and generated multiple cross-overs.

\section{Elliptic vortex loops}

Figure 10 shows the interaction between the vortex loop generated from the elliptic nozzle having $a / b=0.6$ and $P_{4} / P_{1}=12$ with the ejector. The times are given from the instant the incident shock wave initially emerges from the shock tube. The primary reflected wave from the ejector inlet continues upstream and reflects from the lip of the elliptic nozzle (see Figure 10(b)). The secondary reflected wave, marked in Figure 10(c), is a result of this interaction. In the same figure, a secondary vortex loop can be identified in the jet shear layer. The resultant flow interactions appear qualitatively similar to the circular nozzles.

The jet exiting the tube, after the vortex loop has entered the ejector, is accompanied by the generation of intense Mach waves. These waves are generated from the jet shear layer exiting the shock tube, which reflect from the ejector inlet and travel upstream.

The pressure histories of transducers $T 4$ and $T 18$ for the two elliptical nozzles presented in Figure 11 are similar to the circular nozzles and vary only in magnitude. The oscillations in pressure data recorded are due to the wave reflections occurring within the ejector which emanate from the precursor shock front and the jet shear layer. Umeda and Ishiii ${ }^{21,22}$ showed the existence of a rotating Mach cone about the jet axis which is responsible for the acoustic wave generation within the jet shear layer.

\section{Square vortex loop}

The schematic of the diffraction pattern which occurs once the initially planar shock wave from the shock tube arrives at the nozzle exit is shown in Figure 12. In Figure 12, $A N$ is the diffracted shock wave, $A R O$ is the front of the reflected expansion wave which propagates back into the oncoming flow, and $A L$ is the contact surface which separates that part of the flow field processed by the diffracting shock wave from that processed by the incident wave. The sound wave, $A R O$ in Figure 12, is visible in Figure 13(a), as well as the initial stages of development of the square vortex loop.

The two shocks labelled $i$ in Figure 13(b) are reflected from the ejector internal wall which 
interact with the diamond shock structures within the jet behind the primary vortex loop in Figure 13(c). It is the reflection and following diffraction of this shock structure which generates the second vortex loop in Figure 13(d).

Because the frontal area of square vortex loop relative to the ejector inlet is large, once

the secondary vortex loop enters the ejector the flow at the inlet begins to choke. As a consequence of the increased entrainment of secondary flow, the area of the ejector inlet is no longer able to accommodate for the inflow and the flow begins to travel upstream. This is visible when comparing Figures 13(e) and 13(f).

The drop in static pressure at the ejector inlet, shown in Figure 14, is greater for the square vortex loop than the other nozzles studied so far. This is due to the larger size of the square vortex loop. Increase in wall pressure with increasing downstream distance indicates the acceleration of the secondary flow at the inlet region.

\section{Exotic vortex loops}

From analysis of the schlieren photographs for the two exotic nozzles, at various values of diaphragm pressure ratio, it is deduced that the induced flow structures appear similar at different flow Mach numbers. Figure 15 shows the flow features generated from the smaller nozzle $(a / b=0.2)$ at different values of $P_{4} / P_{1}$. The main distinction between the flow features generated by the smaller and larger nozzles occurs later on in the flow development stage. The distinction is identified in Figure 16. When the reflected shock from the ejector inlet interacts with the shock tube exit it leads only to the generation of a reflected shock for the smaller nozzle (Figure 16(a)), whereas for the larger nozzle a secondary vortex loop is also generated.

\section{B. Incident Shock Wave Propagation Through Ejector}

The incident shock Mach numbers through the ejector have been calculated at two different locations with the results given in Table I. The first shock Mach number is deduced from the pressure peaks of transducers $T 4$ and $T 18$ located at the entrance and the exit of the ejector $(50 \mathrm{~cm}$ apart). The second shock Mach number is calculated using the transducers placed close to the exit of the ejector ( $6 \mathrm{~cm}$ apart). 
The incident shock Mach number has also been calculated using the normal shock relation given by Eq. (1) by taking the pressure peak of transducer $T 18$ and assuming $p_{1}=1$ bar .

$$
M_{s}=\sqrt{\frac{\gamma+1}{2 \gamma}\left(\frac{p_{2}}{p_{1}}-1\right)+1}
$$

The shock Mach numbers calculated using Eq. (1) appear to be in better agreement with the flow Mach number obtained from $T 4-T 18$. The reason for the discrepancies of $M_{s}$ between theory and those obtained from $T 16-T 18$ is believed to be due to the greater distance between the ejector internal wall and the transducer location. As the shock passes through the diffuser section it decelerates, but because the induced flow behind the shock front is subsonic, the pressure within the diffuser increases. The increase in pressure behind the incident shock enables the preservation of its strength and hence flow Mach number.

\section{Flow Structures Generated at the Ejector Exit}

Using the high-speed schlieren photographs obtained by the Shimadzu camera, the velocity of the diffracted incident shock wave along with the vortex loop generated from the ejector exit is deduced from plots similar to Figure 17. The Mach numbers are obtained from a linear curve fit. This data is provided in Table II.

Although different nozzles imply different flow Mach numbers at the nozzles' exit, ranging from $M_{s}=1.05$ to 1.62, the incident shock Mach numbers at the ejector exit show a smaller variation in flow Mach number between $M_{s x}=1.02$ and 1.14. The velocity of the propagating vortex loop which is circular in nature is considerably less $\left(U_{T x}\right.$ in Table II). For the exotic nozzle having an axis ratio of 0.2 with $P_{4} / P_{1}=4$ no vortex loop was evident in the schlieren images. The results for the vortex loop translational velocity indicate a dependence on shock tube nozzle area. The square and circular nozzle with $d_{i}=30 \mathrm{~mm}$ result in the highest vortex loop velocities at the ejector exit, whereas the exotic nozzle having axis ratio 0.2 which has a relatively smaller area results in a very slowly propagating vortex loop at the ejector exit.

If the exit nozzle of the shock tube has an area comparable with the inlet of the ejector, it makes more effective usage of the principle operation of the ejector which is to entrain ambient air. The large spreading of the jet leads to better mixing, a statement in agreement with the findings of Hsia et al. ${ }^{23}$ The entrained air increases the momentum of the flow and hence the impulse created at the ejector exit. 
Figure 18 shows a selection of the schlieren photographs which express the main components of the flow created at the exit of the ejector. Similar to the shock diffraction pattern from the shock tube exit, the flow is comprised of a diffracted shock, a vortex loop generated due to the shock diffraction, and finally in Figure 18(d) the remaining debris of the primary vortex loop which entered the ejector.

Another feature which is created at the ejector exit is a secondary vortex identified in Figure 19(a). This vortex is generated when the shock exiting the ejector diffracts from the outer edge of the ejector. The motion of the secondary vortex is identified in relation to the position of the primary vortex in Figures 19(b) and 19(c). Naturally the newly formed vortex is expected to move towards the inlet of the ejector (to the left of the image), but this is not the case. Due to the low pressure region created by the flow exiting the ejector and the circulatory motion of the primary vortex, the secondary vortex is drawn towards the ejector exit where it dissipates soon after by interacting with the high-speed flow along with the waves exiting the ejector (Figure 19(d)).

Examining the diffraction pattern for the square nozzle shown in Figure 20 with a diaphragm pressure ratio of $P_{4} / P_{1}=12$, some of the flow features have already been discussed: the primary vortex and the secondary vortex generated at the ejector outer edge. Due to the multiple diffracting waves present in the flow, a plethora of secondary vortices is generated at the ejector exit which are entrained into the primary vortex core. A flow feature that is specific to the square nozzle and the circular nozzle with $d_{i}=30 \mathrm{~mm}$, and only occurring for a diaphragm pressure ratio of $P_{4} / P_{1}=12$, is the presence of vortex spirals evident in Figures 20(b) and 20(c).

\section{Ejector Performance}

\section{Impulse created by ejector}

The impulse $I$, received by the solid plate, is calculated through the integration of pressure derived as:

$$
I=\int_{t_{1}}^{t_{2}} P d t
$$


where $t_{1}$ is the time at which the shock wave front arrives at the centre of the solid plate. Time $t_{2}$ is taken as the time that the strength of any flow interactions with the plate has diminished and the pressure levels approach the ambient value.

For each diaphragm pressure ratio, $P_{4} / P_{1}$, the total impulse was calculated by the summation of impulses from the pressure traces of all four transducers, such as the pressure history given in Figure 21. The shock wave arrives at the location of the fourth transducer, placed $75 \mathrm{~mm}$ from the centre of the ejector and denoted by the green line, $20 \mu \mathrm{s}$ after arriving at the plate centre. This is due to the initially planar shock front which develops a spherical shape.

The calculated impulses are given in Figure 22. To enable better comparison between the data points, the results have been presented in two subfigures (a) and (b) with the results from the circular nozzle $d_{i}=30 \mathrm{~mm}$ provided as baseline in both subfigures for comparison. The impulse generated by the various nozzles is dependent on the velocity of the vortex ring generated at the ejector exit. This conclusion is arrived at by comparing the vortex ring velocities provided in Table II with the impulses of Figure 22.

\section{Time averaged pressure measurement}

The time averaged internal pressure of an ejector is another way of determining its performance. Since unsteady ejectors obtain their thrust from suction on the inlet, therefore, the time average internal pressure in the best performing ejectors is below ambient.

Table III displays the time averaged pressure of transducer 4 located at the entrance to the ejector. As higher values of $P_{4} / P_{1}$ are examined, the average pressure at the transducer location decreases due to the higher velocity of the primary flow exiting the shock tube. The higher velocity of the primary jet exiting the shock tube produces an area of low pressure and because the ambient air at rest is at a higher pressure air is entrained into the primary jet.

At $P_{4} / P_{1}=4$, the elliptic nozzle 0.4 and exotic nozzle 0.5 lead to the lowest time averaged pressures highlighting the dominance of non-circular jets in improving ejector performance. However, at $P_{4} / P_{1}=8$ it is the square nozzle that creates the lowest internal pressure and hence, better ejector performance. Although the elliptic nozzle nozzle 0.4 and exotic nozzle 0.5 led to a better ejector performance at $P_{4} / P_{1}=4$, they create higher internal pressures 
at $P_{4} / P_{1}=8$ indicative of their lower effectiveness.

At $P_{4} / P_{1}=12$ the three nozzles which lead to the lowest pressures are the circular nozzle with internal diameter $30 \mathrm{~mm}$, the elliptic nozzle with axis ratio 0.6 and the square nozzle. In all three cases the initial shock front diffracted from the nozzles reflects from the ejector inlet and interacts with the nozzles leading to the formation of a new vortex loop. The newly formed vortex loop propagates through the ejector leading to the entrainment more fluid and hence the reduction in pressure.

\section{CONCLUSIONS}

The main objective of incorporating ejectors in propulsive applications, especially PDEs, is for thrust augmentation provided without the need for mechanical and electrical components. The benefit of thrust augmentation arrives from the entrainment of secondary flow by a primary one.

Using exit nozzle geometries other than axisymmetric leads to increased entrainment rates. However, high entrainment rates must be balanced with adequate design considerations since this may lead to the choking of the mass flow into the ejector, as was shown to be the case when studying square vortex loops in the present analysis.

The current study has revealed how the presence of the ejector can affect the primary flow characteristics i.e., the reflected shock wave from the ejector inlet travels upstream creating an induced velocity away from the ejector. This behaviour undermines the efficacy of the primary flow in entraining ambient fluid through the ejector. Also, as this reflected wave interacts with the shock tube exit it leads to the formation of a new vortex loop in some instances or a reflected shock wave in others.

A flow feature which is unique to the circular vortex loop is the separation of the flow at the ejector inlet. This results in the generation of an upstream travelling vortex loop. The upstream travelling flow also plays an important part in the effectiveness of ejectors. The interaction between this flow and the exit of the nozzle leads to the generation of new coherent structures which interact with the ejector.

Although different nozzles imply different flow Mach numbers at the nozzles' exit, ranging from $M_{s}=1.05$ to 1.62 , the flow Mach numbers through the ejector show a smaller variation in flow Mach number between $M_{s}=1.02$ and 1.14 , where $M_{s}=1.02$ corresponds to the 
circular nozzle with internal diameter of $15 \mathrm{~mm}$ with $P_{4} / P_{1}=4$ and $M_{s}=1.14$ corresponds to the circular nozzle with internal diameter of $30 \mathrm{~mm}$ and $P_{4} / P_{1}=12$. The propagation velocity of the vortex ring generated at the ejector exit varies between $U_{T x}=3.5 \mathrm{~m} / \mathrm{s}$ and $35.3 \mathrm{~m} / \mathrm{s}$, where $U_{T x}=3.5 \mathrm{~m} / \mathrm{s}$ corresponds to the circular nozzle with internal diameter of $15 \mathrm{~mm}$ with $P_{4} / P_{1}=4$ and $U_{T x}=35.3 \mathrm{~m} / \mathrm{s}$ corresponds to the circular nozzle with internal diameter of $30 \mathrm{~mm}$ and $P_{4} / P_{1}=12$.

The calculated impulses at the ejector exit, deduced from time integration of the pressure on a solid plate, show that when the circular nozzle with a $30 \mathrm{~mm}$ internal diameter is used at the shock tube exit it results in the greatest level of impulse recorded. This is not unexpected since the dimensions of the ejector were based on a shock tube having an exit nozzle diameter of $30 \mathrm{~mm}$.

Examining the time averaged internal pressure of an ejector is another indication of its performance: the time average internal pressure in the best performing ejectors is below ambient. The present study revealed that the individual nozzles performed best at various flow Mach numbers. At $P_{4} / P_{1}=4$ the elliptic nozzle with axis ratio 0.4 and the exotic nozzle with axis ratio 0.5 created the lowest internal pressures. At $P_{4} / P_{1}=8$ the square nozzle leads to the best performance and at $P_{4} / P_{1}=12$ the circular nozzle with internal diameter $30 \mathrm{~mm}$, the elliptic nozzle with axis ratio 0.6 and the square nozzle lead to the best performance with the circular nozzle dominating slightly over the other two.

Comparison between the impulses measured and the time averaged internal pressures show good correlation at $P_{4} / P_{1}=8$ and 12 , both methods showing the circular, square and elliptic nozzles as the optimum geometry. However, at $P_{4} / P_{1}=4$ the internal pressures show non-circular nozzles dominating whereas the impulses show a clear superiority of the circular nozzle with internal diameter $30 \mathrm{~mm}$.

Further studies will be conducted to analyse the performance of the ejector when the ejector is located at different locations relative to the nozzles' exit. PIV analysis will also be undertaken at the ejector inlet and outlet to determine the effect of the various flow phenomena on the air intake and exhaust. 


\section{Acknowledgments}

The authors are greatly indebted to the technical and administrative staff at the school of MACE in The University of Manchester, and the support of the EPSRC Engineering Instrument Pool, for the loan of the Shimadzu high-speed camera. The authors would like to thank Prof. K. Takayama at the Shock Wave Research Centre for providing the exotic nozzles.

1 Gutmark, E.J., Grinstein, F.F., "Flow control with noncircular jets," Annual Review of Fluid Mechanics Vol. 31, 1999, pp. 239-272.

2 Gutmark, E., Schadow, K.C., Wilson, K.J., "Subsonic and supersonic combustion using noncircular injectors," Journal of Propulsion and Power Vol. 7, No. 2, 1991, pp. 240-249.

3 Gutmark, E., Schadow, K.C., Yu, K.H., "Mixing enhancement in supersonic free shear flows," Annual Review of Fluid Mechanics Vol. 27, 1995, pp. 375-417.

4 Grinstein, F.F., Gutmark, E., Parr, T., "Near field dynamics of subsonic free square jets. A computational and experimental study," Physics of Fluids Vol. 7, No. 6, 1995, pp. 1483-1497.

5 Grinstein, F.F., DeVore, C.R., "Dynamics of coherent structures and transition to turbulence in free square jets," Physics of Fluids Vol. 8, 1996, pp. 1237-1251.

6 Zare-Behtash, H., Kontis, K., Gongora-Orozco, N., Takayama, K., "Compressible vortex loops: Effect of nozzle geometry," International Journal of Heat and Fluid Flow Vol. 30, 2009, pp. $561-576$.

7 Zare-Behtash, H., Gongora-Orozco, N., Kontis, K., "Global visualization and quantification of compressible vortex loops," Journal of Visualization Vol. 12, 2009, pp. 233-240.

8 Eustace, V.A., "A study of two-dimensional supersonic air ejector systems," PhD Thesis, The University of Manchester Institute of Science and Technology, (1969).

${ }^{9}$ Kailasanath, K., "Recent developments in the research on pulse detonation engines," AIAA Journal, Vol. 41, No. 2, 2003, pp. 145-159.

10 Etele, J., Parent, B., Sislian, J.P., "Analysis of increased compression through area constriction on ejector-rocket performance," Journal of Spacecraft and Rockets Vol. 44, No. 2, 2007, pp. $355-364$. 
11 Kontis, K., An, R., Zare-Behtash, H., Kounadis, D., "Head-on collision of shock wave induced vortices with solid and perforated walls," Physics of Fluids Vol. 20, 2008.

12 Brouillette, M., Hebert, C., "Propagation and interaction of shock-generated vortices," Fluid Dynamics Research Vol. 21, 1997, pp. 159-169.

13 Arakeri, J.H., Das, D., Krothapalli, A., Lourenco, L., "Vortex ring formation at the open end of a shock tube: A particle image velocimetry study," Physics of Fluids Vol. 16, 2004, pp. $1008-1019$.

14 Glaser, A. J., Caldwell, N., Gutmark, E., Hoke, J., Bradley, R., Schauer, F., "Experimental study of ejectors driven by a pulse detonation engine," 45th AIAA Aerospace Sciences Meeting and exhibit, 8-11 January, Reno, Nevada 2007.

15 Wilson, J., Sgondea, A., Paxson, D. E., Rosenthal, B. N., "Parametric investigation of thrust augmentation by ejectors on a pulsed detonation tube," Journal of Propulsion and Power Vol. 23, 2007, pp. 108-115.

16 Wilson, J., Sgondea, A., Paxson, D. E., Rosenthal, B. N., "Parametric investigation of thrust augmentation by ejectors on a pulsed detonation tube," Journal of Propulsion and Power Vol. 23, 2007, pp. 108-115.

17 Zare-Behtash, H., Kontis, K., Gongora-Orozco, N., "Experimental investigations of compressible vortex loops," Physics of Fluids Vol. 20, 2008, pp. 126105.

18 Merzkirch, W., "Flow Visualization," Academic Press Inc, 1974.

19 Kontis, K., Kounadis, D., An, R., Zare-Behtash, H., "Head-on collision of shock wave induced vortices with a cylinder and a sphere," International Journal of Heat and Fluid Flow, Vol. 29, 2008, pp. 1380-1392.

20 Ben-Dor, G., "Shock Wave Reflection Phenomena," Springer-Verlag, 1992.

21 Umeda, Y., Ishii, R., "On the sound sources of screech tones radiated from choked circular jets," Journal of the Acoustical Society of America, Vol. 110, No. 4, 2001, pp. 1845-1858.

22 Umeda, Y., Ishii, R., "Existence of Mach cones and helical vortical structures around the underexpanded circular jet in the helical oscillation mode," Journal of the Acoustical Society of America, Vol. 112, No. 1, 2002, pp. 99-107.

23 Hsai, Y.C., Krothpalli, A., Baganoff, D., "Mixing of an underexpanded rectangular jet ejector," Journal of Propulsion and Power, Vol. 4, No. 3, 1988, pp. 256-262. 
TABLE I: Incident shock wave propagation velocity through ejector.

\begin{tabular}{|c|c|c|c|c|}
\hline & $P_{4} / P_{1}$ & $\begin{array}{c}M_{s} \\
T 4-T 18\end{array}$ & $\begin{array}{c}M_{s} \\
T 16-T 18\end{array}$ & $\begin{array}{l}M_{s} \\
P_{s 18}\end{array}$ \\
\hline \multirow{3}{*}{ Circle $30 \mathrm{~mm}$} & 4 & 1.03 & 1.02 & 1.03 \\
\hline & 8 & 1.07 & 0.98 & 1.07 \\
\hline & 12 & 1.09 & 1.1 & 1.1 \\
\hline \multirow{3}{*}{ Circle $15 \mathrm{~mm}$} & 4 & 1.06 & 1.1 & 1.03 \\
\hline & 8 & 1.05 & 1.47 & 1.05 \\
\hline & 12 & 1.08 & 1.04 & 1.07 \\
\hline \multirow{3}{*}{ Ellipse 0.6} & 4 & 0.97 & 0.77 & 1.03 \\
\hline & 8 & 1.07 & 1.26 & 1.07 \\
\hline & 12 & 1.06 & 0.98 & 1.08 \\
\hline \multirow{3}{*}{ Ellipse 0.4} & 4 & 1.03 & 1.17 & 1.03 \\
\hline & 8 & 1.1 & 1.6 & 1.06 \\
\hline & 12 & 1.11 & 1.1 & 1.08 \\
\hline \multirow{3}{*}{ Square } & 4 & 1.02 & 0.88 & 1.03 \\
\hline & 8 & 1.04 & 1.6 & 1.07 \\
\hline & 12 & 1.07 & 1.26 & 1.11 \\
\hline \multirow{3}{*}{ Exotic 0.5} & 4 & 0.93 & 0.93 & 1.02 \\
\hline & 8 & 1.0 & 0.77 & 1.04 \\
\hline & 12 & 1.1 & 1.2 & 1.07 \\
\hline \multirow{3}{*}{ Exotic 0.2} & 4 & 0.97 & 0.88 & 1.02 \\
\hline & 8 & 1.03 & 0.98 & 1.03 \\
\hline & 12 & 1.08 & 1.26 & 1.04 \\
\hline
\end{tabular}


TABLE II: Incident shock wave $\left(M_{s x}\right)$ and vortex loop propagation velocity $\left(U_{T x}\right)$ at ejector exit.

\begin{tabular}{|c|c|c|c|}
\hline & $P_{4} / P_{1}$ & $M_{s x}$ & $U_{T x}[\mathrm{~m} / \mathrm{s}]$ \\
\hline \multirow{3}{*}{ Circle $30 \mathrm{~mm}$} & 4 & 1.04 & 7.8 \\
\hline & 8 & 1.06 & 23.0 \\
\hline & 12 & 1.14 & 35.3 \\
\hline \multirow{3}{*}{ Circle $15 \mathrm{~mm}$} & 4 & 1.02 & 3.5 \\
\hline & 8 & 1.07 & 10.2 \\
\hline & 12 & 1.08 & 16.9 \\
\hline \multirow{3}{*}{ Ellipse 0.6} & 4 & 1.04 & 5.6 \\
\hline & 8 & 1.05 & 11.2 \\
\hline & 12 & 1.13 & 25.1 \\
\hline \multirow{3}{*}{ Ellipse 0.4} & 4 & 1.06 & 5.4 \\
\hline & 8 & 1.08 & 12.5 \\
\hline & 12 & 1.11 & 19.4 \\
\hline \multirow{3}{*}{ Square } & 4 & 1.04 & 10.0 \\
\hline & 8 & 1.04 & 23.4 \\
\hline & 12 & 1.08 & 34.3 \\
\hline \multirow{3}{*}{ Exotic 0.5} & 4 & 1.04 & 3.9 \\
\hline & 8 & 1.05 & 10.0 \\
\hline & 12 & 1.07 & 15.7 \\
\hline \multirow{3}{*}{ Exotic 0.2} & 4 & 1.04 & - \\
\hline & 8 & 1.05 & 4.1 \\
\hline & 12 & 1.05 & 5.5 \\
\hline
\end{tabular}

TABLE III: Time averaged pressure measurements corresponding to transducer 4.

\begin{tabular}{c|c|c|c|c|c|c|c}
\hline$P_{4} / P_{1}$ & Circle $30 \mathrm{~mm}$ & Circle $15 \mathrm{~mm}$ & Ellipse 0.6 & Ellipse 0.4 & Square & Exotic 0.5 & Exotic 0.2 \\
\hline 4 & 0.9990 & 0.9988 & 0.9988 & 0.9980 & 0.9984 & 0.9980 & 0.9997 \\
\hline 8 & 0.9976 & 0.9978 & 0.9977 & 0.9985 & 0.9967 & 0.9986 & 0.9987 \\
\hline 12 & 0.9958 & 0.9975 & 0.9961 & 0.9970 & 0.9959 & 0.9968 & 0.9975 \\
\hline
\end{tabular}




\section{List of Figures}

1 Form and direction of motion of the individual parts of the (a) elliptic and (b) square vortex loops (Zare-Behtash et al. ${ }^{6}$ ).

2 Square vortex loop $P_{4} / P_{1}=8$, (a) seeded flow, (b) velocity contour, (c) vorticity contour (Zare-Behtash et al. $\left.{ }^{7}\right) \ldots \ldots \ldots$. . . . . . . . . . 19

3 The shock tube. . . . . . . . . . . . . . . . . . . . . . . . 19

4 Exotic nozzles' cross section. . . . . . . . . . . . . . . . . . . . 20

5 Schematic of the axis-symmetric ejector (the numbers correspond to transducer tapping locations) . . . . . . . . . . . . . . . . . . . . 20

6 Location of pressure measurements for impulse calculation (dimensions in $\mathrm{mm}$ ). 20

$7 \quad$ Schematic diagram of the schlieren photography setup. . . . . . . . . . . . 21

8 Schlieren images of circular vortex loops interaction with ejector inlet,

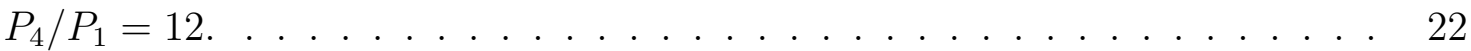

9 Ejector pressure measurements for shock tube with circular nozzles, $P_{4} / P_{1}=$ 12 (transducer locations are given in Figure 5) . . . . . . . . . . . . . . 22

10 Schlieren images of the elliptical vortex loop with axis ratio $a / b=0.6$, $P_{4} / P_{1}=12 \ldots \ldots \ldots \ldots \ldots \ldots \ldots \ldots \ldots \ldots \ldots \ldots \ldots \ldots \ldots$

11 Ejector pressure measurements for shock tube with elliptical nozzles, $P_{4} / P_{1}=$ 12 (transducer locations given in Figure 5) . . . . . . . . . . . . . 23

12 Schematic of the shock diffraction pattern. . . . . . . . . . . . . . . 24

13 Schlieren images of square vortex loop interaction with ejector, $P_{4} / P_{1}=12$. . 24

14 Ejector pressure measurements for shock tube with square nozzle, $P_{4} / P_{1}=12$ (transducer locations given in Figure 5) . . . . . . . . . . . . . . . . 25

15 Schlieren images of the exotic vortex loops interaction with ejector for $a / b=0.2 .25$

16 Schlieren images of the exotic vortex loops interaction with ejector for

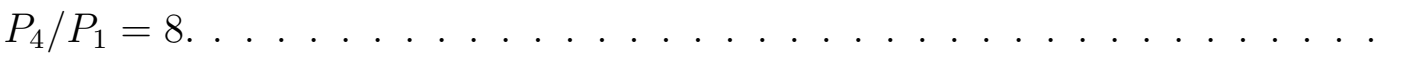

17 Shock wave and vortex loop propagation at the ejector exit for various values of driver pressure, $P_{4}$, for the circular nozzle $d_{i}=30 \mathrm{~mm} \ldots \ldots \ldots$

18 Schlieren images of the flow pattern unfolding at the ejector exit for the circular nozzle $d_{i}=30 \mathrm{~mm}, P_{4} / P_{1}=12 \ldots \ldots \ldots \ldots 27$ 
19 Schlieren images of the flow pattern unfolding at the ejector exit for the circular nozzle $d_{i}=15 \mathrm{~mm}, P_{4} / P_{1}=12 \ldots \ldots \ldots \ldots 27$

20 Schlieren images of the flow pattern unfolding at the ejector exit for the square nozzle, $P_{4} / P_{1}=12 \ldots \ldots \ldots \ldots \ldots \ldots \ldots \ldots$

21 Total pressure measured $100 \mathrm{~mm}$ from the ejector exit, at various distance from the plate centre, for the circular nozzle shock tube $d_{i}=30 \mathrm{~mm}, P_{4} / P_{1}=12.28$

22 Total impulses measured for various shock tube exit geometries at different diaphragm pressure ratios. . . . . . . . . . . . . . . . . . . . . 29 


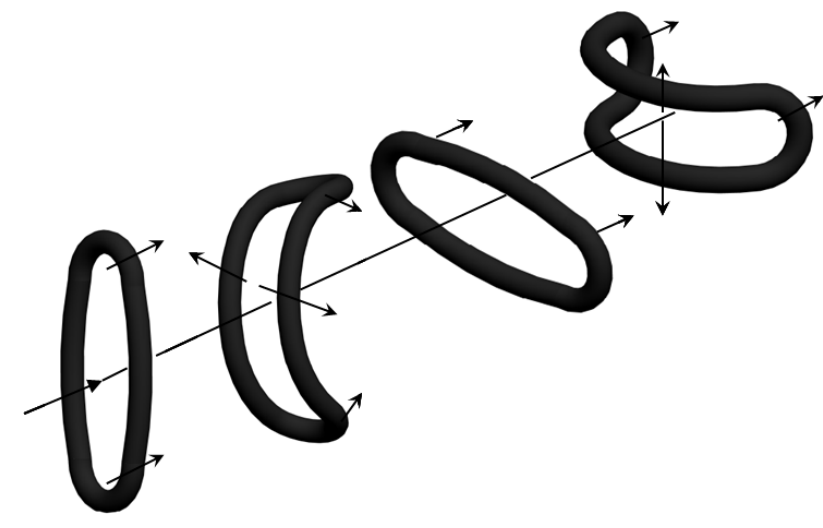

(a)

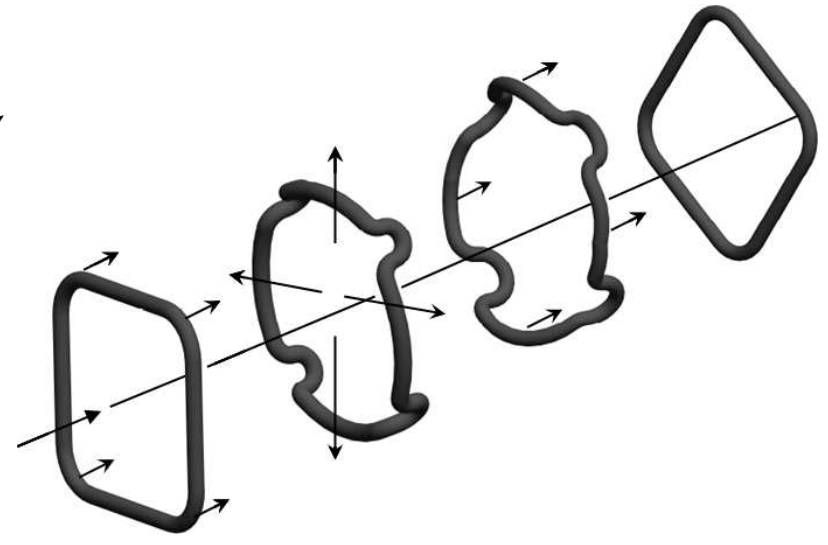

(b)

FIG. 1: Form and direction of motion of the individual parts of the (a) elliptic and (b) square vortex loops (Zare-Behtash et al. ${ }^{6}$ ).
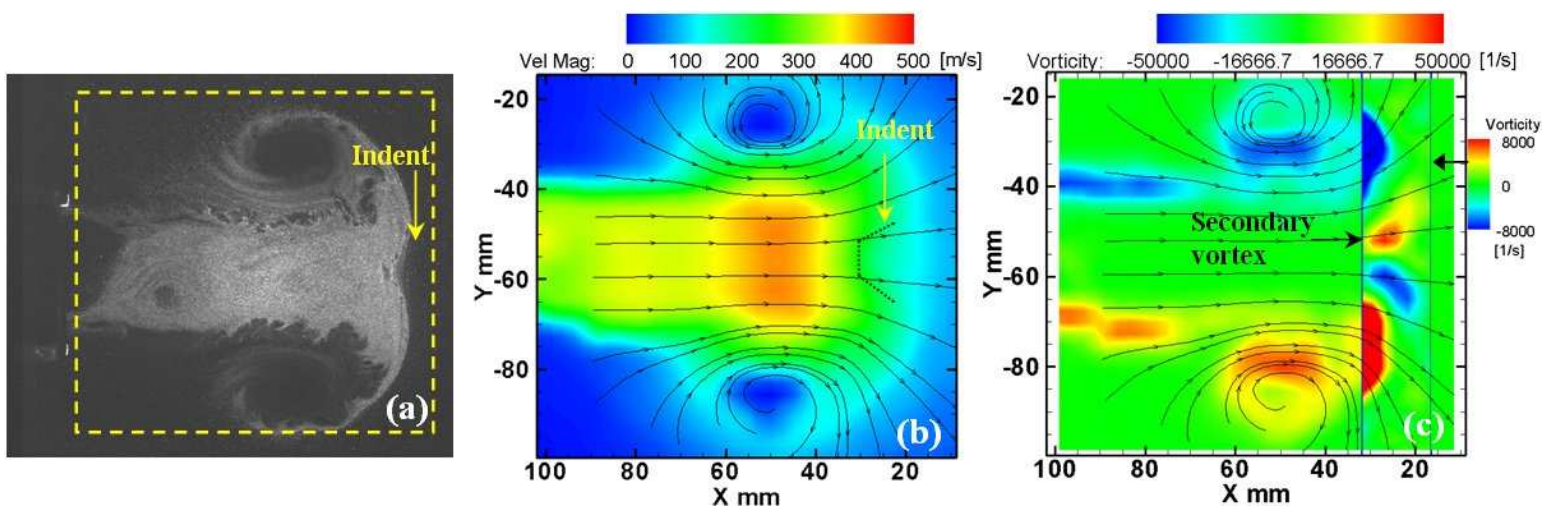

FIG. 2: Square vortex loop $P_{4} / P_{1}=8$, (a) seeded flow, (b) velocity contour, (c) vorticity contour (Zare-Behtash et al. ${ }^{7}$.

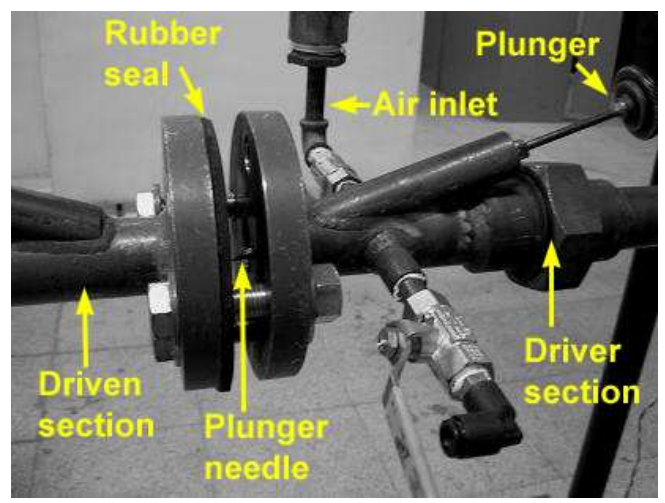

FIG. 3: The shock tube. 


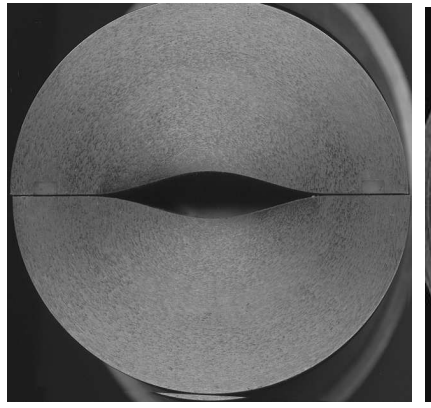

(a) $a / b=0.2$

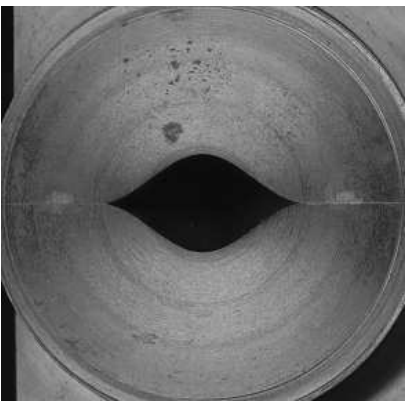

(b) $a / b=0.5$

FIG. 4: Exotic nozzles' cross section.

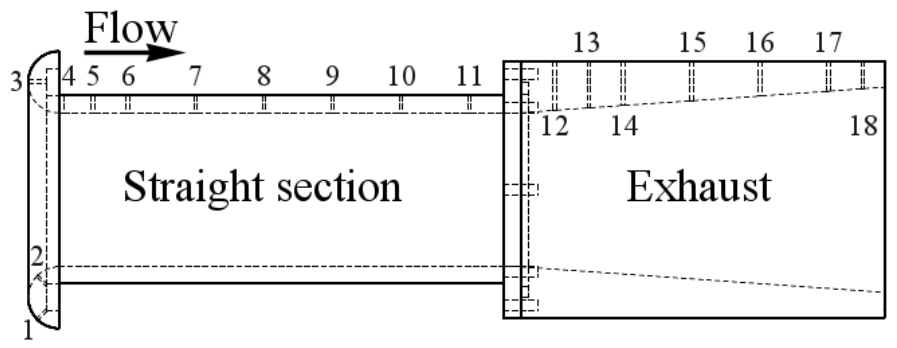

FIG. 5: Schematic of the axis-symmetric ejector (the numbers correspond to transducer tapping locations).

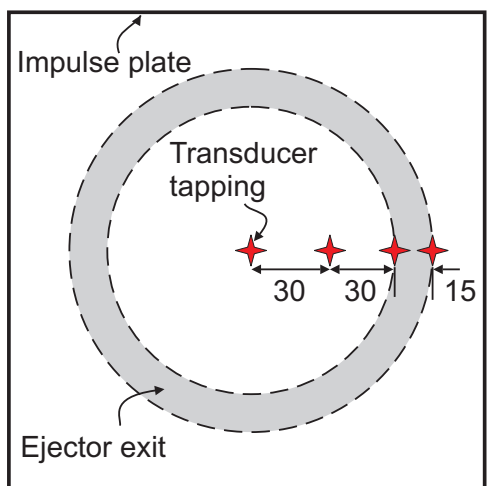

FIG. 6: Location of pressure measurements for impulse calculation (dimensions in $\mathrm{mm}$ ). 


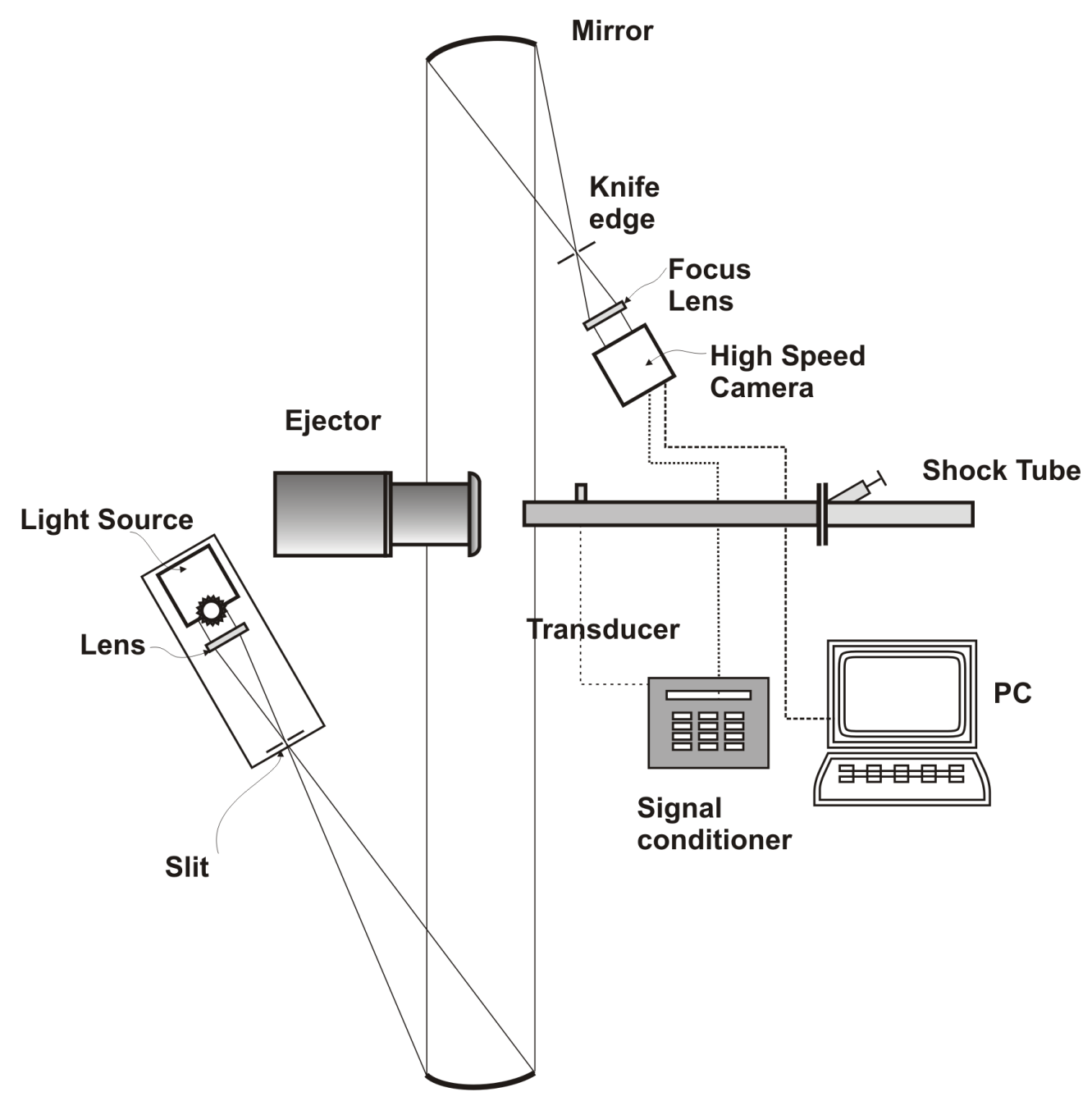

FIG. 7: Schematic diagram of the schlieren photography setup. 


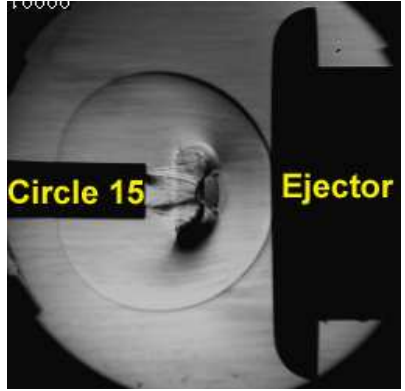

(a)

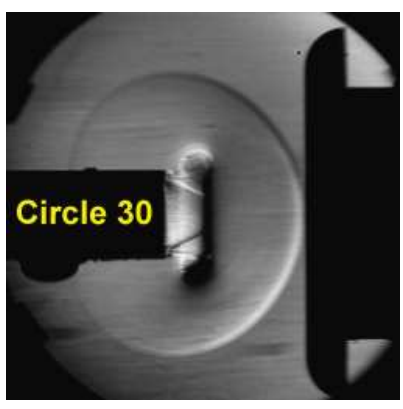

(e)

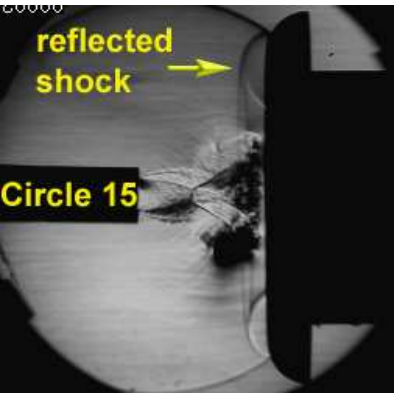

(b)

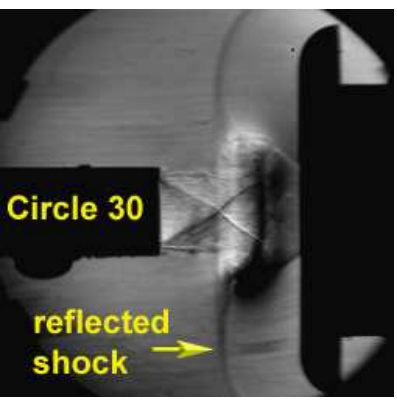

(f)

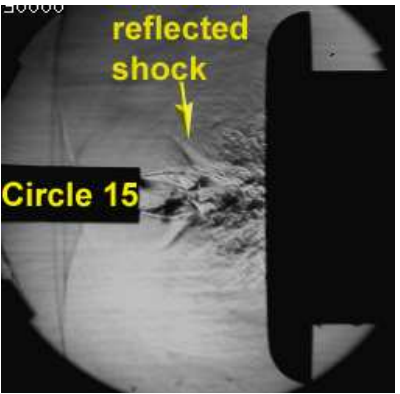

(c)

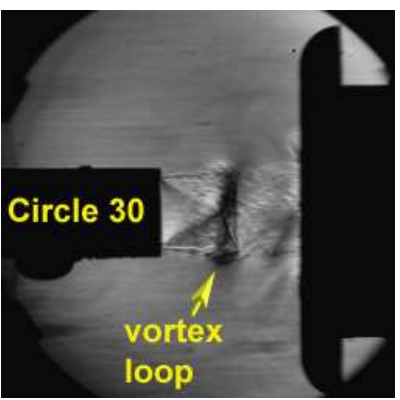

(g)

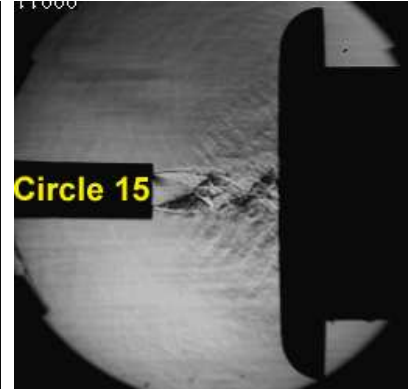

(d)

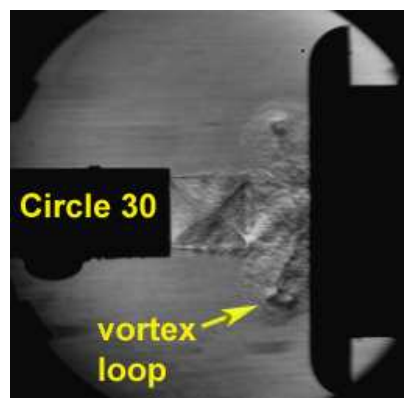

(h)

FIG. 8: Schlieren images of circular vortex loops interaction with ejector inlet, $P_{4} / P_{1}=12$.

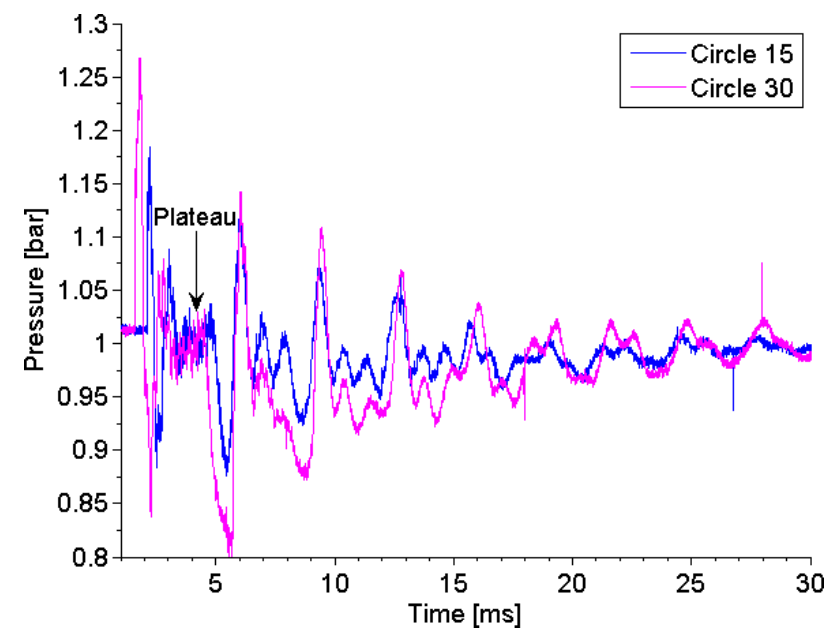

(a)Transducer 4

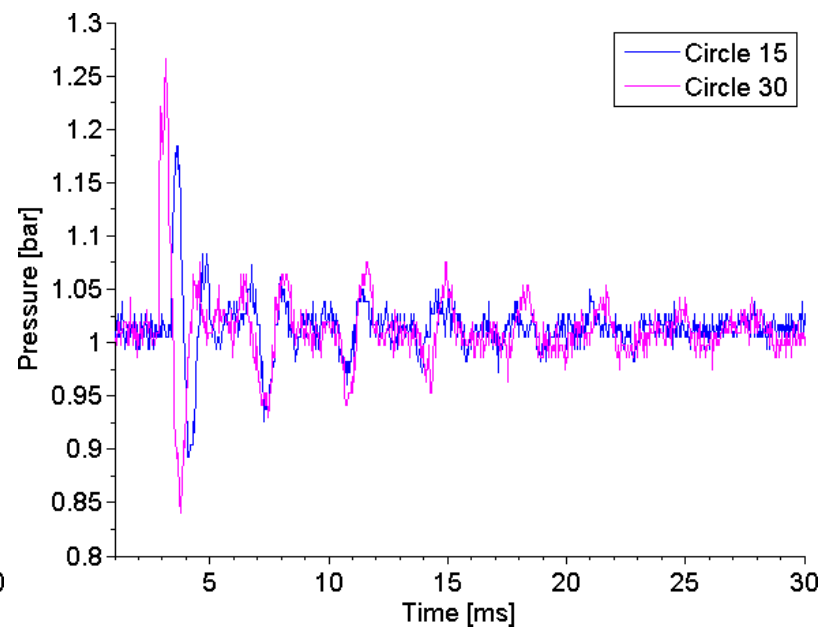

(b)Transducer 18

FIG. 9: Ejector pressure measurements for shock tube with circular nozzles, $P_{4} / P_{1}=12$ (transducer locations are given in Figure 5). 


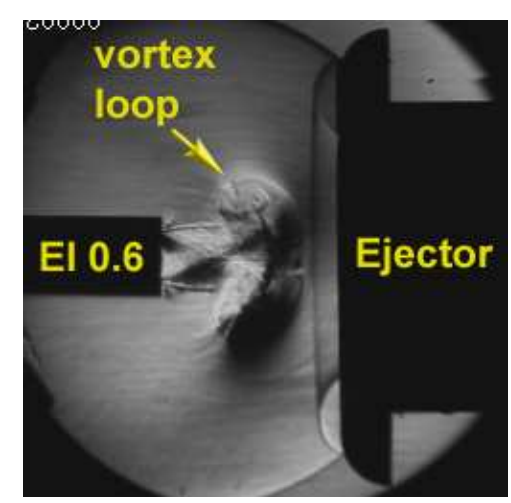

(a) $t=272 \mu \mathrm{s}$

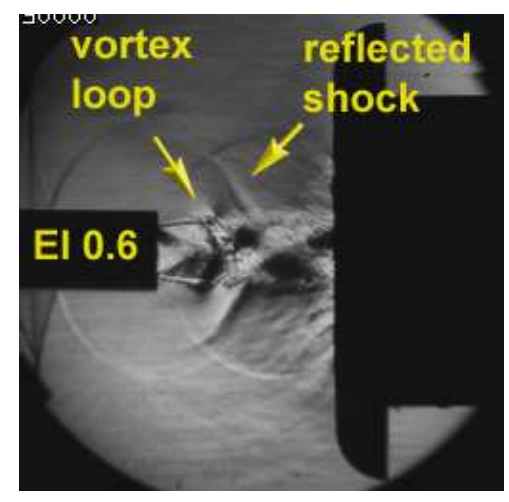

(c)t $=544 \mu \mathrm{s}$

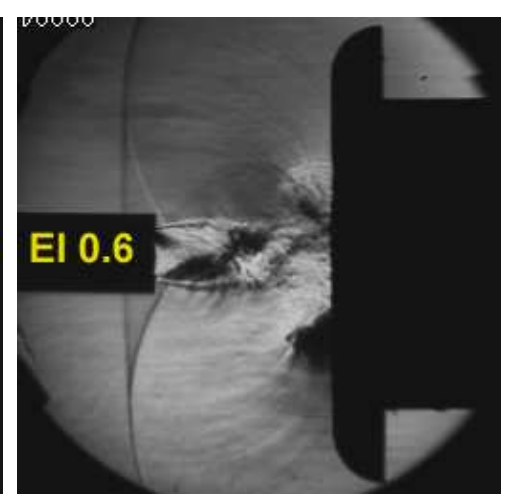

(b)t $=448 \mu \mathrm{s}$

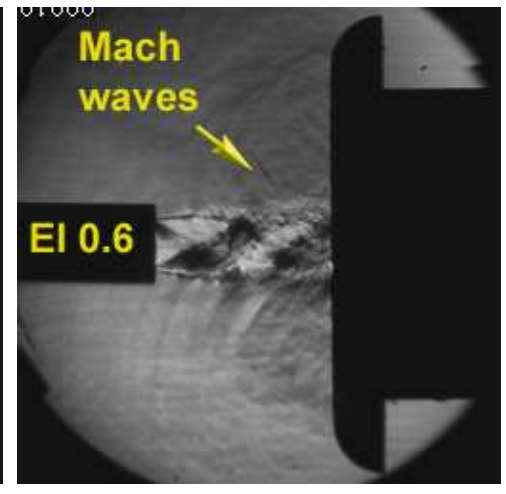

(d) $t=1040 \mu \mathrm{s}$

FIG. 10: Schlieren images of the elliptical vortex loop with axis ratio $a / b=0.6, P_{4} / P_{1}=12$.

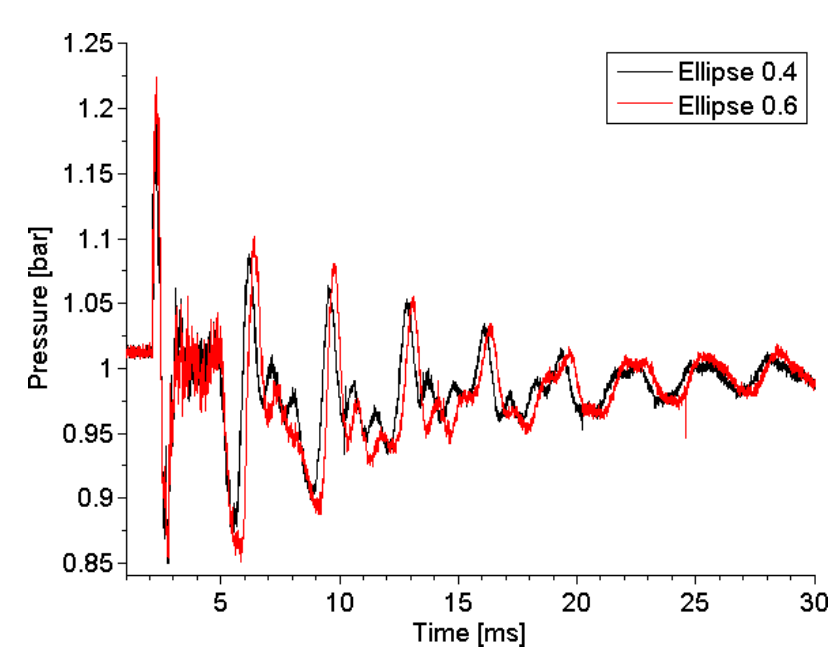

(a)Transducer 4

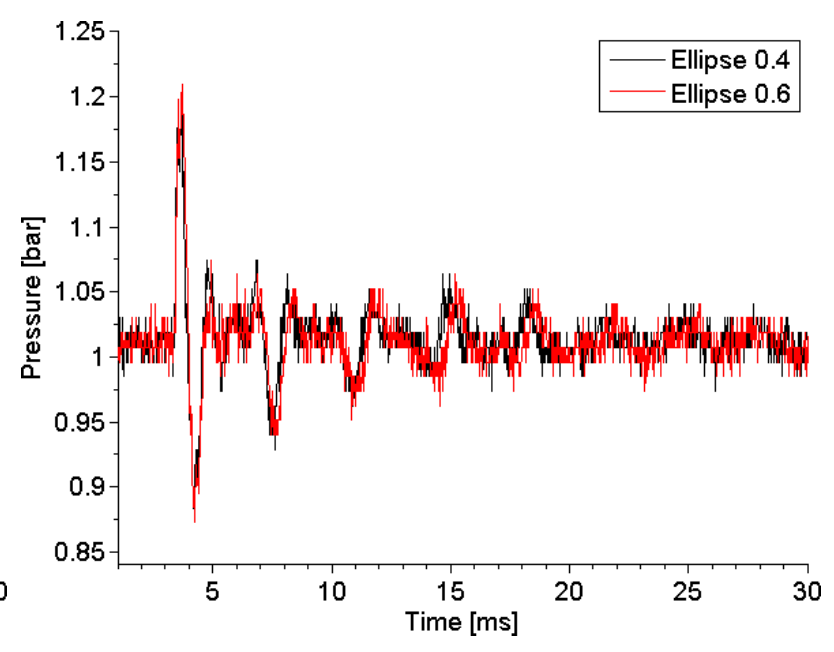

(b)Transducer 18

FIG. 11: Ejector pressure measurements for shock tube with elliptical nozzles, $P_{4} / P_{1}=12$ (transducer locations given in Figure 5). 


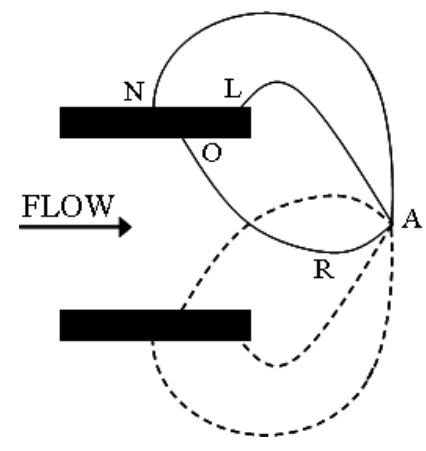

FIG. 12: Schematic of the shock diffraction pattern.
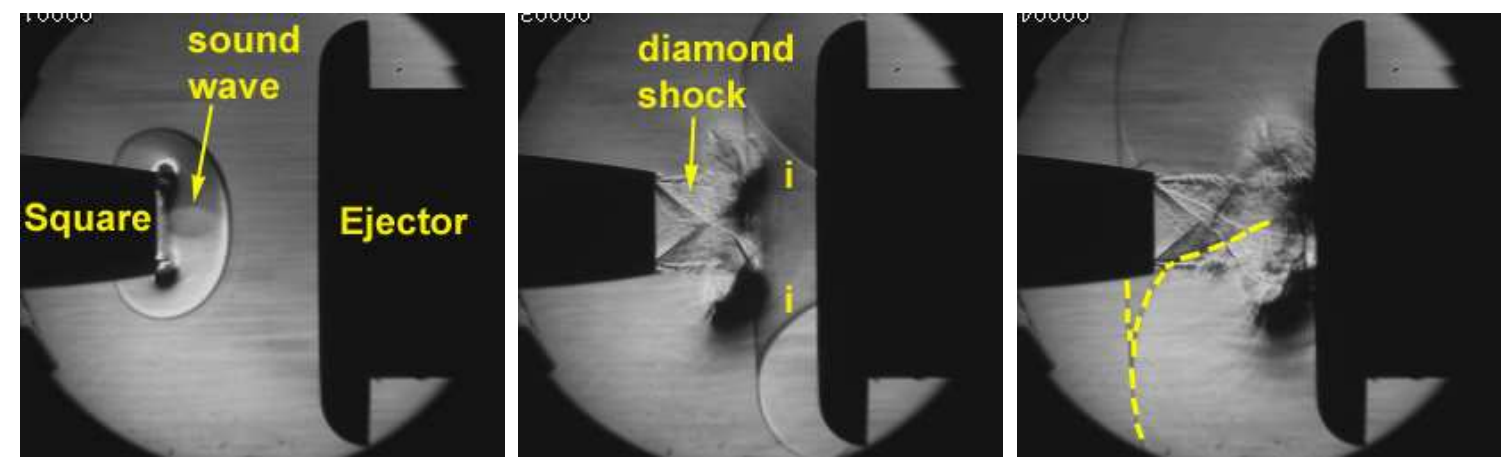

(a) $t=144 \mu \mathrm{s}$

(b) $t=352 \mu \mathrm{s}$

(c) $t=480 \mu \mathrm{s}$
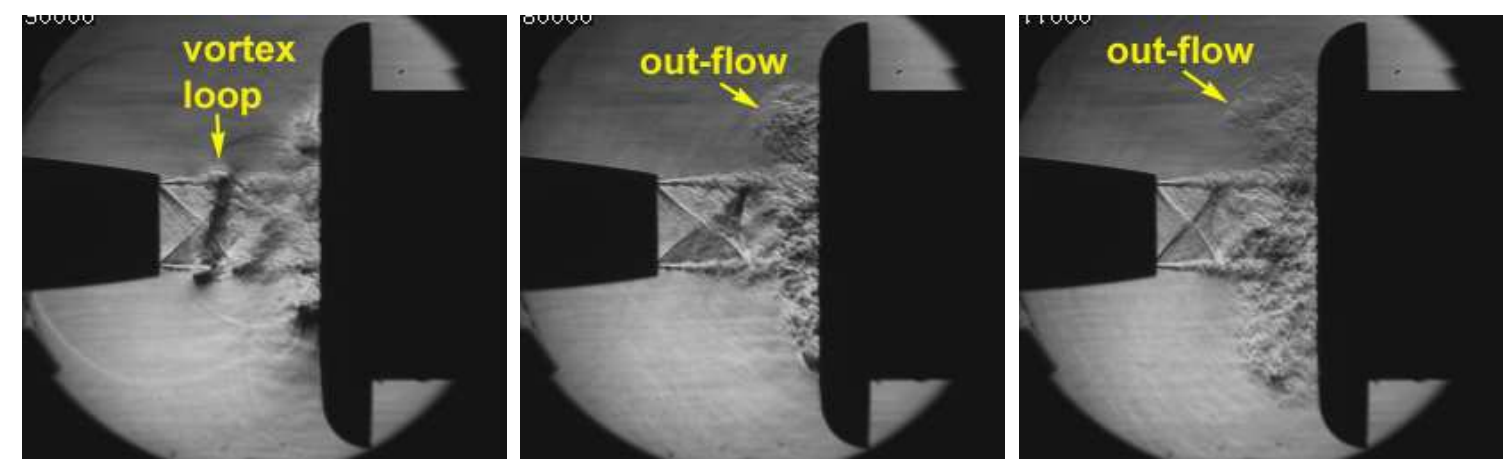

(d) $t=608 \mu \mathrm{s}$

(e) $t=896 \mu \mathrm{s}$

(f) $t=1152 \mu \mathrm{s}$

FIG. 13: Schlieren images of square vortex loop interaction with ejector, $P_{4} / P_{1}=12$. 


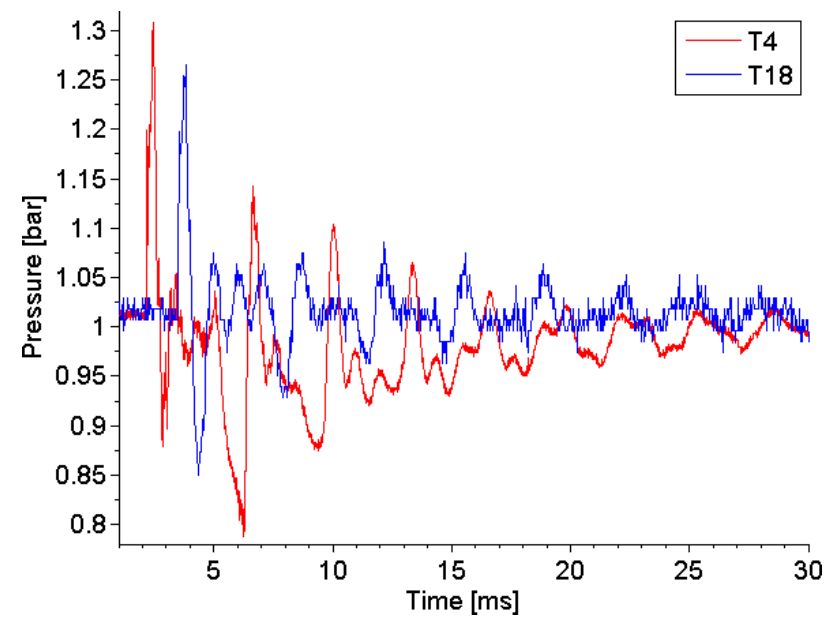

FIG. 14: Ejector pressure measurements for shock tube with square nozzle, $P_{4} / P_{1}=12$ (transducer locations given in Figure 5).

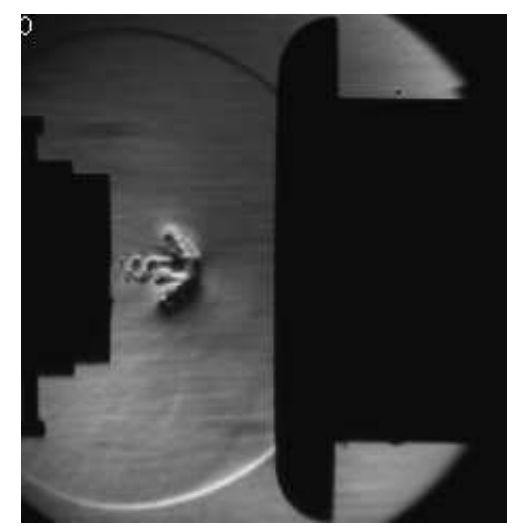

(a) $P_{4} / P_{1}=4$

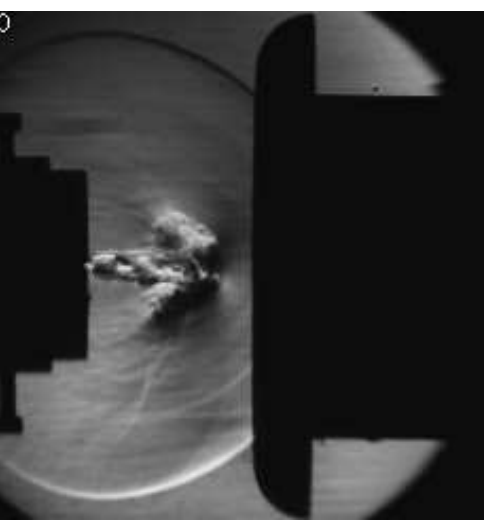

(b) $P_{4} / P_{1}=8$

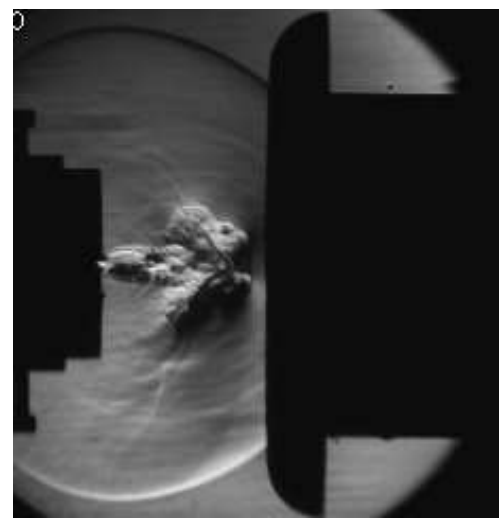

(c) $P_{4} / P_{1}=12$

FIG. 15: Schlieren images of the exotic vortex loops interaction with ejector for $a / b=0.2$.

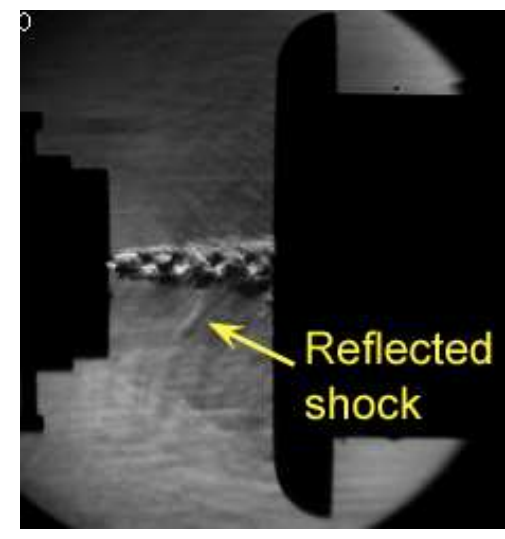

(a) $a / b=0.2$

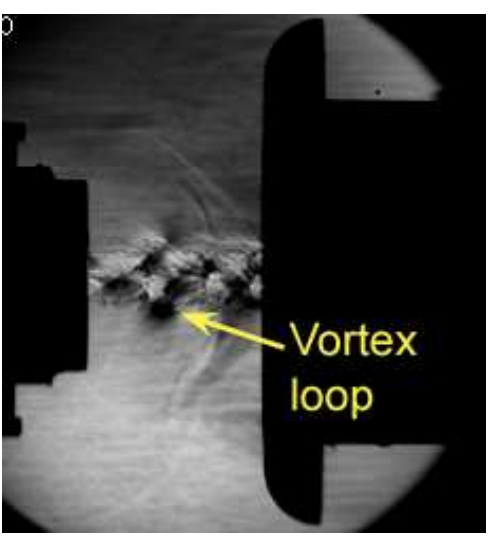

(b) $a / b=0.5$

FIG. 16: Schlieren images of the exotic vortex loops interaction with ejector for $P_{4} / P_{1}=8$. 


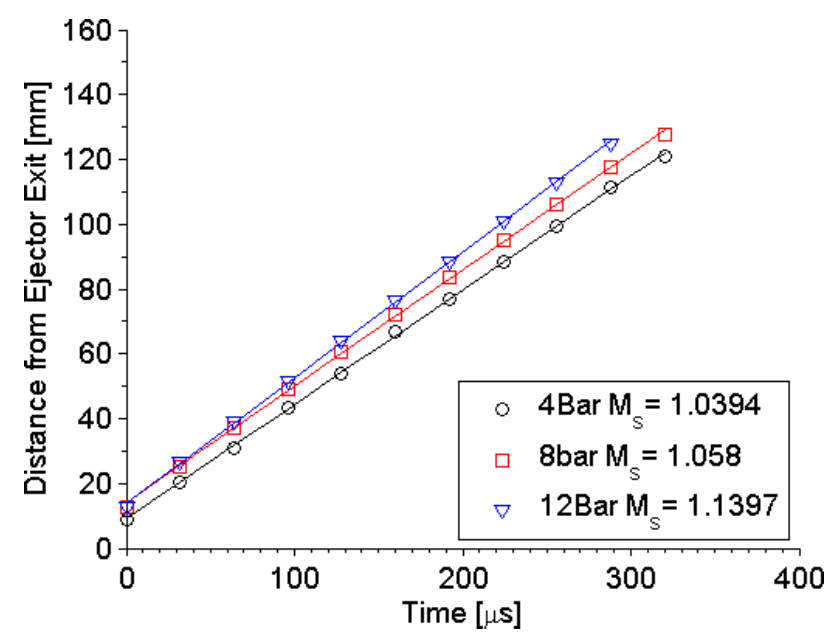

(a)Shock propagation

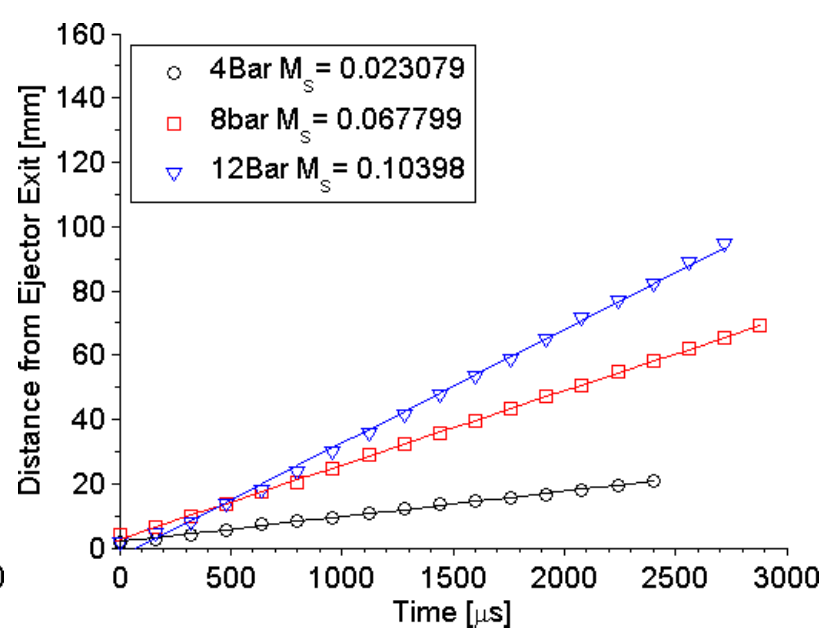

(b)Vortex loop propagation

FIG. 17: Shock wave and vortex loop propagation at the ejector exit for various values of driver pressure, $P_{4}$, for the circular nozzle $d_{i}=30 \mathrm{~mm}$. 


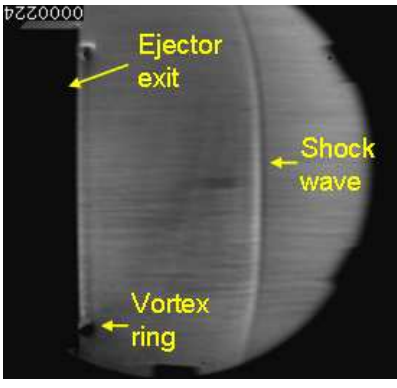

(a) $t=224 \mu \mathrm{s}$

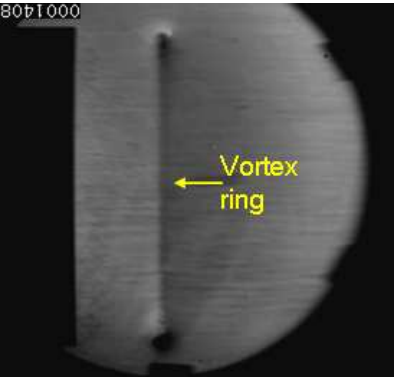

(b) $t=1408 \mu \mathrm{s}$

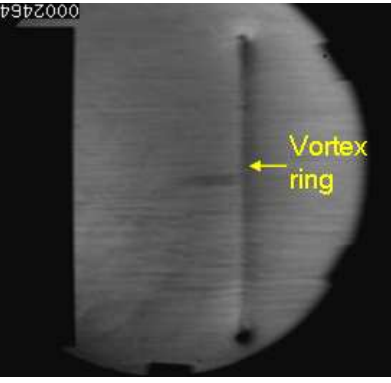

(c) $t=2464 \mu \mathrm{s}$

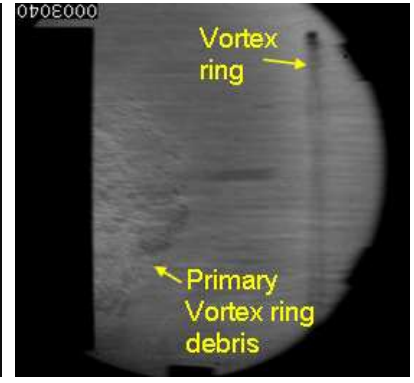

(d) $t=3040 \mu \mathrm{s}$

FIG. 18: Schlieren images of the flow pattern unfolding at the ejector exit for the circular nozzle $d_{i}=30 \mathrm{~mm}, P_{4} / P_{1}=12$.

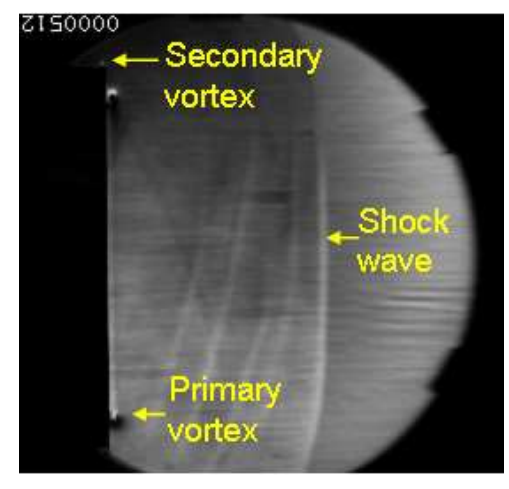

(a) $t=224 \mu \mathrm{s}$

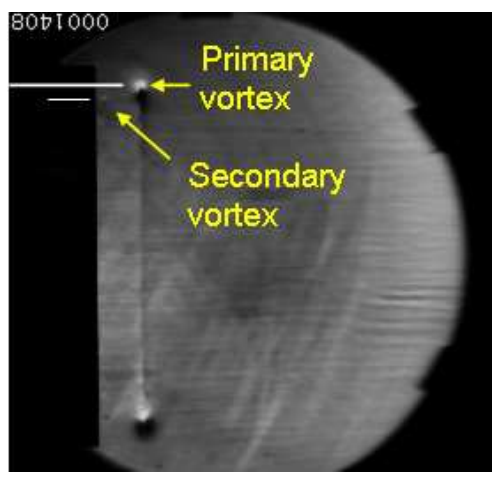

(c) $t=1120 \mu \mathrm{s}$

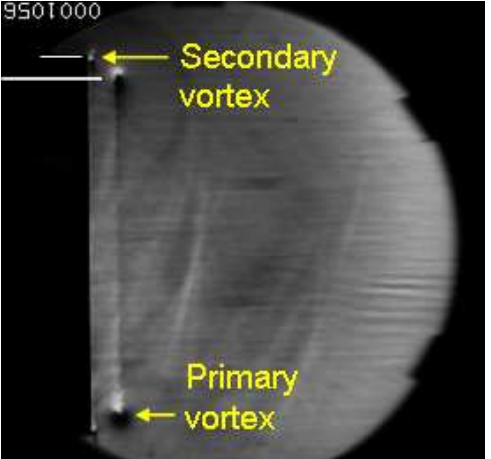

(b) $t=768 \mu \mathrm{s}$

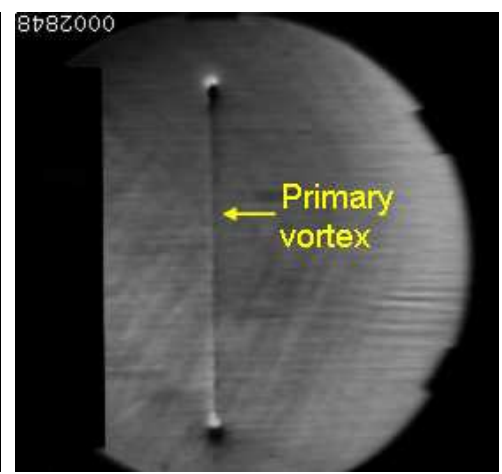

(d) $t=2560 \mu \mathrm{s}$

FIG. 19: Schlieren images of the flow pattern unfolding at the ejector exit for the circular nozzle $d_{i}=15 \mathrm{~mm}, P_{4} / P_{1}=12$. 


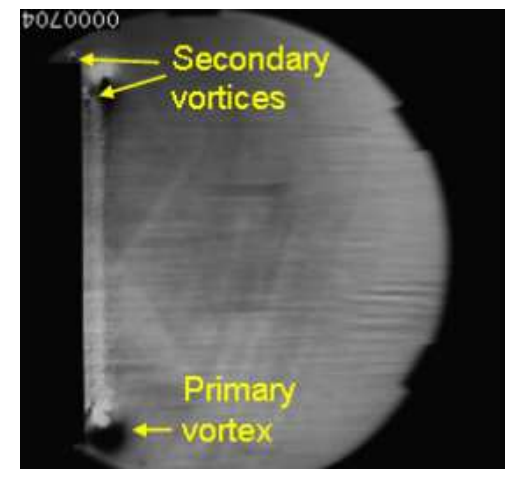

(a)t $=448 \mu \mathrm{s}$

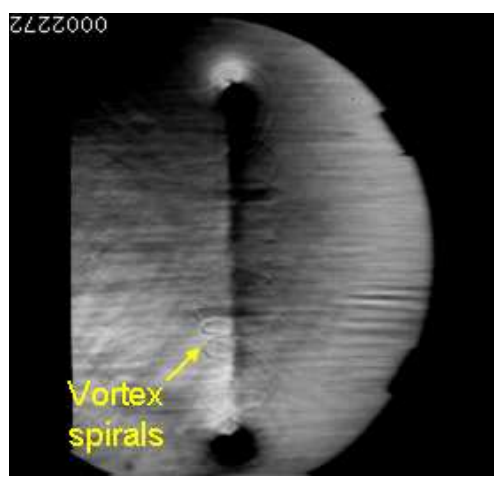

(c) $t=2016 \mu \mathrm{s}$

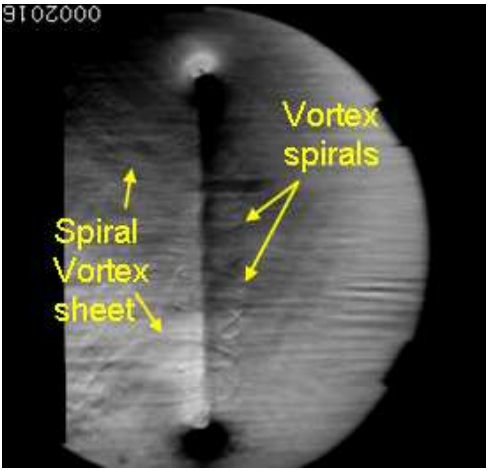

(b) $t=1760 \mu \mathrm{s}$

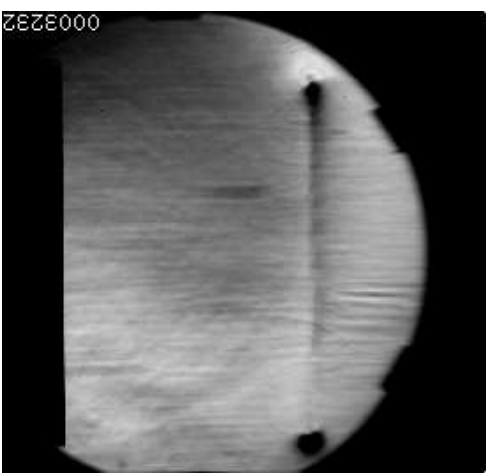

(d) $t=2976 \mu \mathrm{s}$

FIG. 20: Schlieren images of the flow pattern unfolding at the ejector exit for the square nozzle, $P_{4} / P_{1}=12$.

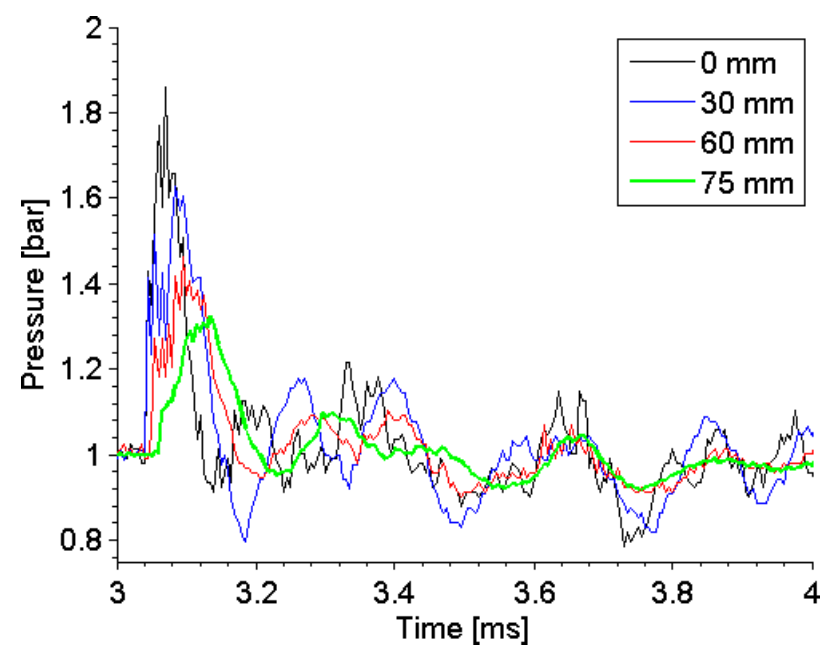

FIG. 21: Total pressure measured $100 \mathrm{~mm}$ from the ejector exit, at various distance from the plate centre, for the circular nozzle shock tube $d_{i}=30 \mathrm{~mm}, P_{4} / P_{1}=12$. 


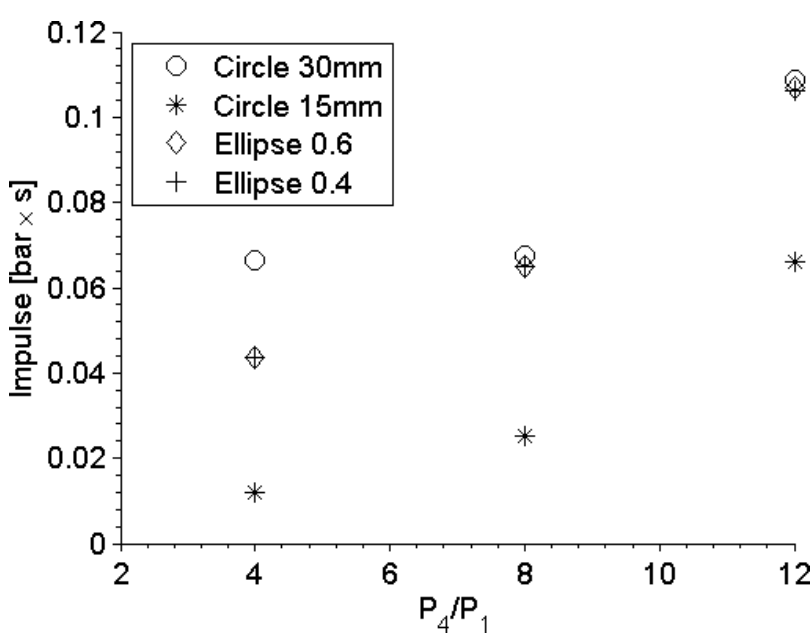

(a)

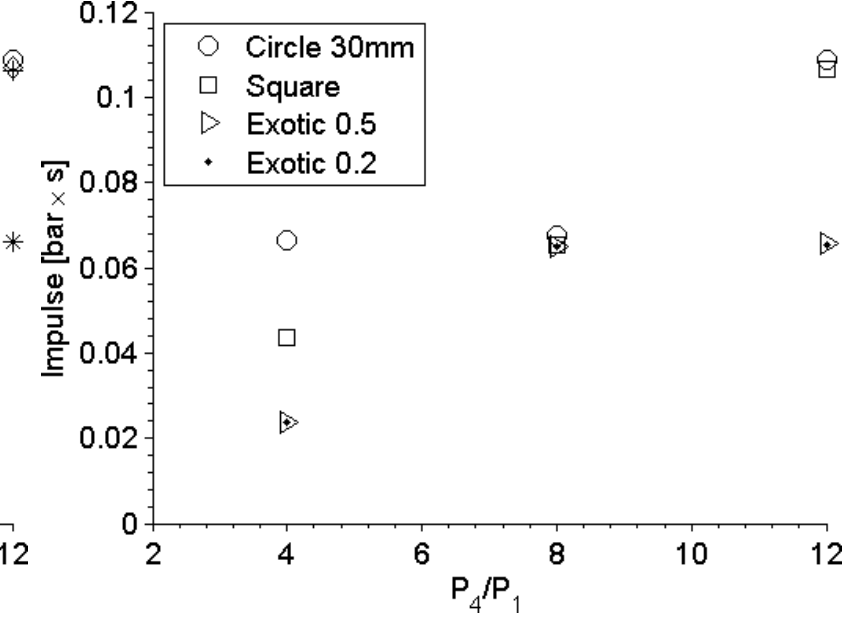

(b)

FIG. 22: Total impulses measured for various shock tube exit geometries at different diaphragm pressure ratios. 